Acta Theriologica 44 (3): 233-242, 1999.

PL ISSN 0001-7051

\title{
Allozyme genetic distances and evolutionary relationships in marsupials of North and South America
}

\author{
Georgina E. BARRANTES and Lidia DALEFFE
}

\begin{abstract}
Barrantes G. E. and Daleffe L. 1999. Allozyme genetic distances and evolutionary relationships in marsupials of North and South America. Acta Theriologica 44: 233-242.

Allozyme genetic distances and variability were studied by horizontal starch gel electrophoresis in 6 species of marsupials from North and South America representing 4 different genera. Twenty-one presumptive loci were assessed in a total of 151 specimens. Only 1 of 21 loci was found to be monomorphic in the whole sample. Phenetic and cladistic interspecific analysis coincided in rendering two sharply differentiated subgroups: one comprising species of the genus Didelphis Linnaeus, 1758 (D. marsupialis Linnaeus, $1758, D$. virginiana Kerr, 1792 and D. albiventris Lund, 1840), and the other comprising Monodelphis dimidiata (Wagner, 1847), Lestodelphys halli (Thomas, 1921) and Lutreolina crassicaudata (Desmarest, 1804). No relationships between the bradytelic condition, the karyotype stability of this group, and genetic variability were found. On the other hand, the existence of species with brief life span such as Lestodelphys halli and Monodelphis dimidiata (Marmosini tribe) and species with long life span (Didelphini tribe) allowed us to test the hypothesis which correlates generation-time with genetic variability. We conclude that a general explanation for genetic variability must involve more than just generation-time.
\end{abstract}

GIBE, Departamento de Ciencias Biológicas, Facultad de Ciencias Exactas y Naturales, Universidad de Buenos Aires, Pabellón II, $4^{\circ}$ piso, Ciudad Universitaria, Nuñez, 1428 Buenos Aires, Argentina, e-mail: mortells@mail.retina.ar

Key words: marsupials, allozymes, systematic relationships

\section{Introduction}

Marsupials (metatherians) and eutherians are the only two groups of viviparous mammals. Didelphidae (Marsupialia) constitutes a discrete family of great interest to students of mammalian evolution, because it not only includes primitive and unspecialized living therians, but also its members may represent the original stock of both the Australasian and the South American metatherian radiations (Clemens 1968 and Lillengraven 1969). Probably its distribution could be dated to the Late Cretaceous, ie more than 75 million years ago (Clemens 1979).

Present addresses: Instituto de Neurociencia, Departamento de Ciencias Biológicas, FCEyN, Universidad de Buenos Aires, Pabellón II, $4^{\circ}$ piso, Ciudad Universitaria, Nuñez, 1428 Buenos Aires, Argentina (GEB); Departamento de Biología, Ciclo Básico Común, Universidad de Buenos Aires, Pabellón III, Ciudad Universitaria, Nuñez, 1428 Buenos Aires, Argentina (LD) 
Didelphidae includes three subfamilies, one of which, Didelphinae, is further divided into three tribes: Didelphini, Metachirini and Marmosini (Reig et al. 1985). Living members of the Didelphidae comprise some 76 species classified in about a dozen genera, which are a prominent element of the Neotropical fauna and represent a wide range of niches within the small carnivore adaptive zone (Gardner 1973, Reig et al. 1977, 1985). Therefore, didelphids are an excellent material for the study of evolutionary patterns in a primitive group of mammals. Nevertheless, didelphids have received comparatively little attention.

Even though morphological character studies have been used to approach systematic-evolutionary studies in mammals, the great diversity and the notable divergence found in the didelphids have been shown to be an obstacle for their use. In addition to this difficulty, there is the karyotypic homogeneity. All the species of marsupials of the American superfamily Didelphoidea have been found to fall into one of three basically similar karyotypes (Reig et al. 1972, 1977). These three different karyotypes are characterized by particular chromosome numbers in the diploid set (14, 18 or 22) and chromosome morphology.

Allozyme electrophoresis can be a useful taxonomic tool that allows comparisons over a wide range of taxonomic diversity. The study of soluble proteins coded by structural genes has been applied only to isolated marsupial groups, the majority being Australian (Richardson et al. 1973, Baverstock et al. 1977, 1979 and 1980). Therefore, in the present work we report an allozymic study by means of electrophoretic techniques including five South American and one North American didelphid species whose phylogenetic relationships remain unclear. Representatives from the Didelphidae family were also used as a model to test the relationships between the bradytelic condition, the karyotype stability found in this group (Reig et al. 1977), and genetic variability. On the other hand, the existence of species with brief life spans such as Lestodelphys halli and Monodelphis dimidiata (Marmosini tribe) and species with long life spans (Didelphini tribe) allowed us to test the hypothesis which correlates generation-time with genetic variability.

\section{Material and methods}

Tissue samples from 151 specimens representing 4 genera and 6 species of marsupials: Didelphis marsupialis Linnaeus, 1758, D. virginiana Kerr, 1792, D. albiventris Lund, 1840, Monodelphis dimidiata (Wagner, 1847), Lestodelphys halli (Thomas, 1921), and Lutreolina crassicaudata (Desmarest, 1804) were analysed by horizontal starch-gel electrophoresis. Animals were captured in the field with National live-traps in Argentina, United States and Venezuela. Table 1 gives details of the species and samples studied.

Specimens were killed by ether inhalation and samples of liver and kidney were frozen and stored in liquid air containers. Preparation of homogenates, electrophoretic procedures and protein staining were performed following Barrantes et al. (1993). Enzymes encoded by twenty-one presumptive loci were examined for all population samples. Enzymes, presumptive loci detected, tissues examined, and buffers employed during the electrophoresis run are listed in Table 2. Presumptive alleles were designed alphabetically by their relative mobility with ' $a$ ' representing the allelic variant migrating furthest anodally. All differences in electrophoretic mobility were assumed to be of genetic origin and inherited in a Mendelian fashion. All differences in mobility were confirmed in side-by-side comparisons 
Table 1. Summary of species used for allozyme investigations. D. - Didelphis, L. - Lutreolina, M. Monodelphis. $n$ - total number of specimens captured per locality, Arg - Argentina, USA - United States of America, Ven - Venezuela. Collector's field numbers and museum catalogue numbers are available for all specimens. $2 \mathrm{n}$ - diploid chromosome number. ${ }^{*}$ - karyotype data was obtained as described by Reig et al. (1977) for all the species with the exception of Lestodelphys halli (M. A. Barros, pers. comm.). Specimens captured in the United States were kindly provided by Dr Allan Dickerman.

\begin{tabular}{|c|c|c|c|c|c|}
\hline Species & $n$ & Locality & Country & Coordinate & $2 n^{*}$ \\
\hline D. albiventris & 34 & Mar del Plata, Buenos Aires & Arg & $38^{\circ} 16^{\prime} \mathrm{S}, 57^{\circ} 47^{\prime} \mathrm{W}$ & 22 \\
\hline D. marsupialis & 12 & Guaraunos, Sucre & Ven & $10^{\circ} 42^{\prime} \mathrm{N}, 64^{\circ} 00^{\prime} \mathrm{W}$ & 22 \\
\hline D. marsupialis & 30 & Pto. Península, Misiones & Arg & $26^{\circ} 00^{\prime} \mathrm{S}, 54^{\circ} 37^{\prime} \mathrm{W}$ & 22 \\
\hline D. marsupialis & 21 & Valle de Sartenejas, Miranda & Ven & $09^{\circ} 43^{\prime} \mathrm{N}, 66^{\circ} 06^{\prime} \mathrm{W}$ & 22 \\
\hline D. virginiana & 15 & Dane County, Wisconsin & USA & $43^{\circ} 12^{\prime} \mathrm{N}, 89^{\circ} 30^{\prime} \mathrm{W}$ & 22 \\
\hline Lestodelphys halli & 2 & Los Menucos, Río Negro & Arg & $40^{\circ} 23^{\prime} \mathrm{S}, 68^{\circ} 37^{\prime} \mathrm{W}$ & 14 \\
\hline L. crassicaudata & 13 & Mar del Plata, Buenos Aires & Arg & $38^{\circ} 16^{\prime} \mathrm{S}, 57^{\circ} 47^{\prime} \mathrm{W}$ & 22 \\
\hline M. dimidiata & 24 & Mar del Plata, Buenos Aires & Arg & $38^{\circ} 16^{\prime} \mathrm{S}, 57^{\circ} 47^{\prime} \mathrm{W}$ & 18 \\
\hline
\end{tabular}

with electromorphs of similar mobility. Therefore, genotypes of each sample were directly determined from differential electromobility.

Allele frequencies, genetic variability measures, Rogers (1972) distance coefficient $\left(D_{\mathrm{R}}\right)$ and Nei's $(1972,1978)$ genetics distances $\left(D_{\mathrm{N}}\right)$ were performed using the BIOSYS-1 programme (Swofford and Selander 1981). Interspecific phenetic analysis was done using UPGMA (Sneath and Sokal 1973). Maximum parsimony phylogenetic analysis was performed employing Swofford's (1985) PAUP programme. As in a previous work (Barrantes et al. 1993) we used the model of independent alleles of Mickevich and Johnson (1976). We chose the PAUP BANDB (branch - and - bound) and UNORDERED options. The analysis was carried out through an absence/presence matrix based on the allelic frequency data of the variable loci ( 20 out of 21 loci since $L d h-1$ was monomorphic in all taxa).

Table 2. Proteins, loci, tissues and gel running conditions for samples of the genus Didelphis, Lutreolina, Lestodelphys and Monodelphis. K - kidney, L - liver, E.C.No. - enzyme commission number, E.C. - electrophoretic conditions, 1 - Tris EDTA Borate II (pH 9.0, 150 V, 16 hr), 2 - Tris Citrate I (pH 6.3-6.7, $190 \mathrm{~V}, 4 \mathrm{hr})$

\begin{tabular}{lllll}
\hline Proteins & Loci & Tissue & E.C.No. & E.C. \\
\hline Aspartate aminotransferase & Aat $-1,-2$ & $\mathrm{~L}$ & 2.6 .1 .1 & 1 \\
Esterase & Est -1 to -5 & $\mathrm{~K}, \mathrm{~L}$ & 3.1 .1 .1 & 1,2 \\
Fumarase & Fum-1, -2 & $\mathrm{~L}$ & 4.2 .1 .12 & 1 \\
Glucose-6 phosphate dehydrogenase & G-6pdh & $\mathrm{L}$ & 1.1 .1 .49 & 1 \\
Glyceraldehyde phosphate dehydrogenase & Gapdh & $\mathrm{L}$ & 1.2 .1 .12 & 1 \\
Isocitrate dehydrogenase & Idh-1 & $\mathrm{K}$ & 1.1 .1 .42 & 2 \\
Lactate dehydrogenase & Ldh-1,-2 & $\mathrm{K}$ & 1.1 .1 .27 & 2 \\
Malate dehydrogenase & Mdh-1 & $\mathrm{K}$ & 1.1 .1 .37 & 2 \\
Malic enzyme & Me & $\mathrm{L}$ & 1.1 .1 .40 & 1 \\
Peptidase & Pep-1,-2 & $\mathrm{L}$ & 3.4 .11 & 1 \\
Phosphoglucomutase & Pgm-1,-2 & $\mathrm{K}$ & 2.7 .5 .1 & 2 \\
Xanthine dehydrogenase & Xdh & $\mathrm{L}$ & 1.2 .1 .37 & 1 \\
\hline
\end{tabular}




\section{Results}

The general pattern of allozymic variation showed an average of 2.3 alleles per locus since 49 alleles were identified at the 21 presumptive loci. Only 1 of the 21 loci $(L d h-1)$ was found to be monomorphic in our whole sample. Table 3 shows the allele frequencies for the remaining 20 loci $(95.2 \%)$ where more than one allelic variant was found.

With respect to the variation within taxa, values for the mean sample size per locus $(N)$, mean number of alleles per locus per individual $(A)$, percent of loci polymorphic per population $(P, 95 \%$ criterion) and mean observed and expected heterozygosity per locus $(H)$, are provided in Table 4 . Values of $H$ expected under Hardy-Weinberg equilibrium and based on individual samples estimates were in most of the cases higher than the observed ones, varying from $2.5 \%$ to $13.9 \%$. The exceptions were D. marsupialis (Guaraunos) and L. halli since they displayed no heterozygosity at all.

The average opossum-like marsupial populations examined are polymorphic at $14.8 \%$ of their loci. However there is a wide range in these values across all taxa

Table 3. Allele frequencies for 20 variable loci. Electromorphs and their frequencies observed in species of marsupials.

\begin{tabular}{|c|c|c|c|c|c|c|}
\hline Locus & $\begin{array}{l}\text { Didelphis } \\
\text { albiventris }\end{array}$ & $\begin{array}{l}\text { Didelphis } \\
\text { marsupialis }\end{array}$ & $\begin{array}{l}\text { Didelphis } \\
\text { virginiana }\end{array}$ & $\begin{array}{l}\text { Lestodelphys } \\
\text { halli }\end{array}$ & $\begin{array}{c}\text { Lutreolina } \\
\text { crassicaudata }\end{array}$ & $\begin{array}{c}\text { Monodelphis } \\
\text { dimidiata }\end{array}$ \\
\hline Est-1 & $a(.91), b$ & $a(.09), b(.88), c$ & $a(.37), b(.53), c$ & $d$ & $d$ & $d$ \\
\hline Est-2 & $a(.97), \mathrm{b}$ & $a(.92), b$ & $a(.81), b$ & $c$ & $c$ & $c$ \\
\hline Est-3 & $b$ & $b$ & $b$ & $a$ & $a$ & $a$ \\
\hline Est-4 & $b$ & $b$ & $b$ & $a$ & $a$ & $a$ \\
\hline Est-5 & $b$ & $b$ & $b$ & $a$ & $a$ & $a$ \\
\hline$L d h-1$ & $a$ & $a$ & $a$ & $a$ & $a$ & $a$ \\
\hline$L d h-2$ & $a(.98), b$ & $a$ & $a$ & $a$ & $a$ & $a$ \\
\hline Aat-1 & $a$ & $a$ & $a$ & $b$ & $a$ & $b$ \\
\hline Aat-2 & $a$ & $a$ & $a$ & $b$ & $b$ & $b$ \\
\hline Pep-1 & $b$ & $a(.05), b$ & $b$ & $b$ & $c$ & $c$ \\
\hline Pep-2 & $a$ & $a(.84), b$ & $a(.25), b$ & $a$ & $a$ & $a(.94), b$ \\
\hline G-6pdh & $a(.97), b$ & $a$ & $a$ & $c$ & $a(.58), b$ & $c$ \\
\hline $\mathrm{Me}$ & $a(.76), b$ & $a(.38), b$ & $b$ & $b$ & $a$ & $a(.36), b$ \\
\hline Gapdh & $a$ & $a$ & $a$ & $b$ & $a$ & $b$ \\
\hline Pgm-1 & $a$ & $a(.57), b$ & $a$ & $a$ & $a$ & $a$ \\
\hline Pgm-2 & $a(.03), b$ & $a(.54), b$ & $a(.45), b$ & $\mathrm{c}$ & $a(.13), b$ & $b$ \\
\hline$X d h$ & $a(.28), b$ & $a(.95), b$ & $a(.50), b$ & $\mathrm{c}$ & $c$ & $a(.07), b$ \\
\hline Fum-1 & $a$ & $a$ & $a$ & $b$ & $a$ & $b$ \\
\hline Fum-2 & $b$ & $a(.27), b$ & $b$ & $c$ & $c$ & $c$ \\
\hline Idh-1 & $a$ & $a$ & $a$ & $b$ & $a$ & $a$ \\
\hline$M d h-1$ & $a$ & $a$ & $a$ & $b$ & $a(.88), b$ & $a$ \\
\hline
\end{tabular}


Table 4. Measures of electromorphic variability within 6 species of marsupials. D. - Didelphis, L. Lutreolina, $M$. - Monodelphis. $N$ - mean sample size per locus, $A$ - mean number of alleles per locus, $P$ - percent of loci polymorphic per population (95\% criterion); and two measures of mean heterozygosity per locus $(H)$ : direct count (Observ.), and Hardy-Weinberg unbiased expectation (Expect.).

\begin{tabular}{|c|c|c|c|c|c|c|}
\hline \multirow{2}{*}{ Taxon } & \multirow{2}{*}{ Population } & \multirow{2}{*}{$N$} & \multirow{2}{*}{$A$} & \multirow{2}{*}{$P$} & \multicolumn{2}{|c|}{$H$} \\
\hline & & & & & Observ. & Expect. \\
\hline D. albiventris & Mar del Plata & 28.2 & 1.3 & 19.2 & 0.029 & 0.084 \\
\hline \multirow[t]{3}{*}{ D. marsupialis } & Guaraunos & 11.6 & 1.0 & 0.0 & 0.000 & 0.000 \\
\hline & Pto. Península & 19.2 & 1.1 & 8.0 & 0.007 & 0.025 \\
\hline & Valle de Sartenejas & 18.8 & 1.4 & 32.0 & 0.076 & 0.139 \\
\hline D. virginiana & USA & 11.3 & 1.3 & 26.9 & 0.076 & 0.121 \\
\hline Lestodelphys halli & Los Menucos & 2.0 & 1.0 & 0.0 & 0.000 & 0.000 \\
\hline L. crassicaudata & Mar del Plata & 9.9 & 1.2 & 20.0 & 0.032 & 0.063 \\
\hline M. dimidiata & Mar del Plata & 18.9 & 1.1 & 12.0 & 0.009 & 0.029 \\
\hline
\end{tabular}

examined, with mean $P$ values varying from $0.0 \%$ (D. marsupialis from Guaraunos, L. halli) to $32.0 \%$ (D. marsupialis from Valle de Sartenejas).

The phenetic relationships among taxa were examined through Rogers' and Nei's genetic distances among species (Table 5). Fig. 1 shows UPGMA phenograms based on Rogers' ( $D_{\mathrm{R}}$, upper panel) and Nei's $\left(D_{\mathrm{N}}\right.$, lower panel) genetic distances, with cophenetic correlation coefficients of 0.954 and 0.901 , respectively. The two phenograms showed almost concordant topologies and similar distance values. Within the opossums, two main and well-separated clusters appear. One comprises all the populations of $D$. marsupialis together with $D$. albiventris and $D$. virginiana. The other cluster encompasses $L$. crassicaudata, $L$. halli and M. dimidiata, the later two more closely related. The difference between Nei and Rogers based phenograms is that in the former, D. albiventris is the most differentiated of the Didelphis cluster, whilst in the latter D. marsupialis from Valle de Sartenejas is the most distant.

Table 5. Matrix of Rogers' and Nei's genetic distances above and below diagonal, respectively.

\begin{tabular}{lcccccccc}
\hline Population & 1 & 2 & 3 & 4 & 5 & 6 & 7 & 8 \\
\hline 1. D. albiventris & - & 0.162 & 0.055 & 0.154 & 0.104 & 0.680 & 0.540 & 0.711 \\
2. D. marsupialis (Guaraunos) & 0.144 & - & 0.116 & 0.178 & 0.129 & 0.602 & 0.464 & 0.740 \\
3. D. marsupialis (Pto. Península) & 0.050 & 0.094 & - & 0.155 & 0.106 & 0.636 & 0.508 & 0.714 \\
4. D. marsupialis (Valle de Sartenejas) & 0.095 & 0.111 & 0.100 & - & 0.133 & 0.702 & 0.517 & 0.749 \\
5. D. virginiana & 0.056 & 0.075 & 0.053 & 0.078 & - & 0.648 & 0.532 & 0.722 \\
6. Lestodelphys halli & 1.126 & 0.919 & 0.993 & 1.182 & 1.013 & - & 0.276 & 0.257 \\
7. L. crassicaudata & 0.753 & 0.591 & 0.684 & 0.673 & 0.725 & 0.291 & - & 0.414 \\
8. M. dimidiata & 1.246 & 1.356 & 1.253 & 1.603 & 1.309 & 0.281 & 0.525 & - \\
\hline
\end{tabular}




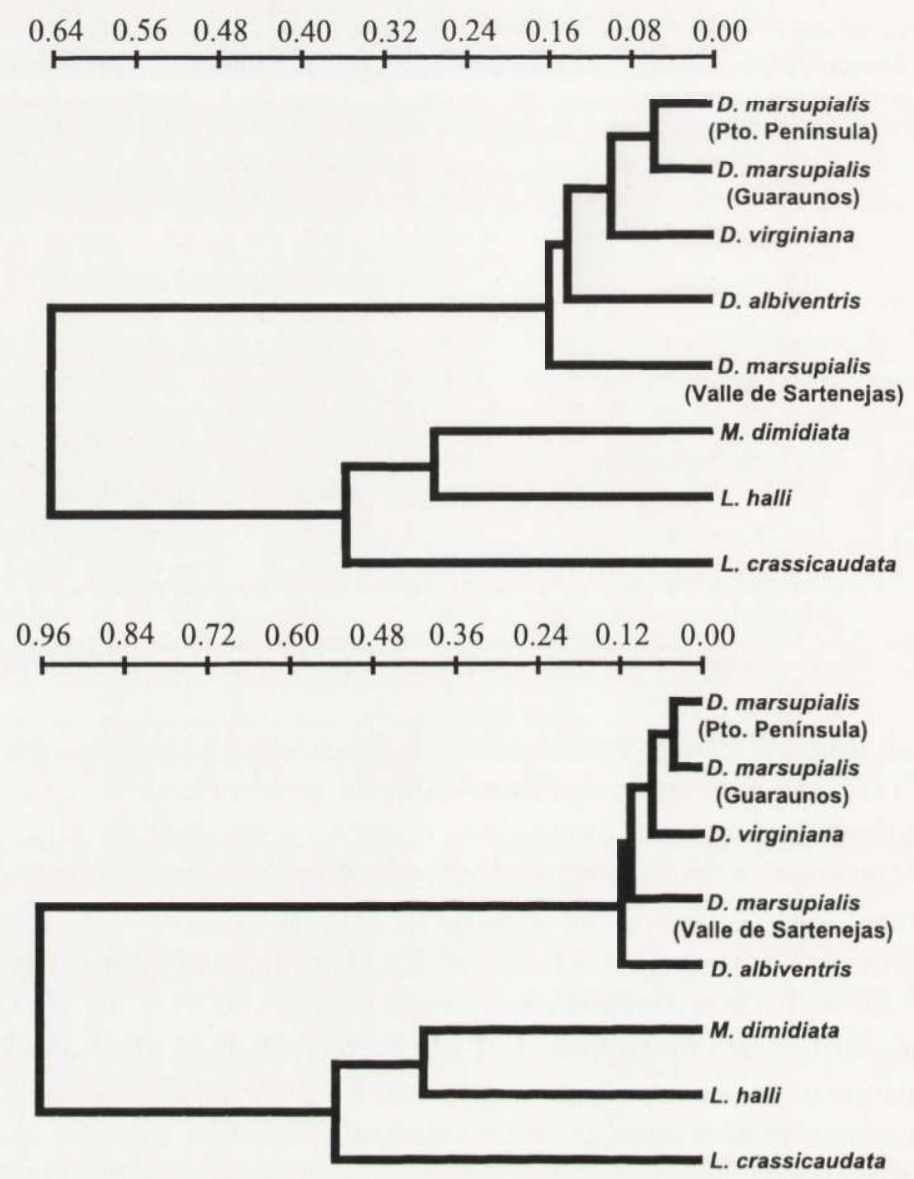

Fig. 1. UPGMA phenogram of 6 opossum species belonging to 4 different genera based on Roger's ( $D_{\mathrm{R}}$ upper panel) and Nei's $\left(D_{\mathrm{N}}\right.$, lower panel) distance matrices. Cophenetic correlation coefficient 0.954 and 0.901 respectively for $D_{\mathrm{R}}$ and $D_{\mathrm{N}}$.

Only one most-parsimonious cladogram was found in the phylogenetic analysis using the PAUP programme, (Fig. 2). This cladogram was congruent with the UPGMA phenograms based on Rogers' $\left(D_{\mathrm{R}}\right)$ and Nei's $\left(D_{\mathrm{N}}\right)$ genetic distances in that $M$. dimidiata, $L$. halli and $L$. crassicaudata constitute an inner subclade. Species of Didelphis were characterized by 9 exclusive alleles: $E s t-1^{a}, E s t-1^{b}, E s t-2^{a}$, Est $-2^{b}, E s t-3^{b}$, Est $-4^{b}$, Est $-5^{b}$, Aat- $2^{a}$, and Fum- $2^{b}$. D. marsupialis shared with D. virginiana the allele $E s t-1^{c}$ which was absent in all other taxa. The grouping of $M$. dimidiata, $L$. halli and $L$. crassicaudata was supported with 8 unique alleles: $E s t-1^{d}, E s t-2^{c}, E s t-3^{a}, E s t-4^{a}, E s t-5^{a}$, Aat $-2^{b}, F u m-2^{c}$, and $M d h-1^{b}$. In addition, the subcluster formed by $M$. dimidiata, $L$. halli was supported by 4 exclusive alleles: G-6pdh ${ }^{c}, A a t-1^{b}$, Gapdh $^{b}$, and Fum-1 ${ }^{b}$ as well as by the lack of 5 alleles (Fig. 2). 


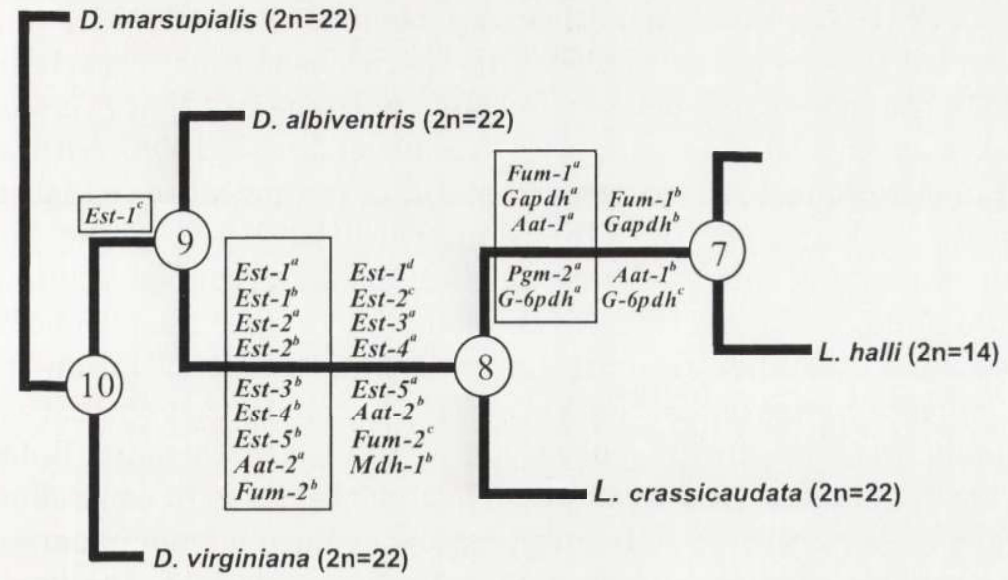

Fig. 2. Cladogram. Consistency index $=0.833$. In the branches are shown those alleles supporting each clade. Alleles enclosed in rectangles indicate that the clade is supported by the loss of them. Numbers in nodes correspond to the hypothetical taxonomic units.

\section{Discussion}

A feature of the Didelphidae is the small number of chromosomal patterns found in the family despite their morphological distinctiveness. Therefore, we shall discuss the allozymic variability in the context of the karyotypic and morphological characteristics of the analysed taxa.

The karyotypic data available for Didelphis have lumped the genera within the diploid set 22. In our study we found that, according to genetic distances (Fig. 1), D. marsupialis, $D$. virginiana and $D$. albiventris are grouped together. Moreover, the cladogram shows that the genus Didelphis has only one hypothetical ancestor (HTU 9 of Fig. 2; remember that the cladogram is unrooted). However, $L$. crassicaudata whose diploid number is also 22 (Wainberg and Fronza 1969) is grouped in the phenograms (Fig. 1) with $M$. dimidiata and L. halli whose diploid number sets are 18 (Reig and Bianchi 1969) and 14 (M. A. Barros, pers. comm.), respectively. These results would at first glance look unexpected since $L$. crassicaudata has been associated with Didelphis, Philander, and Chironectes through karyological and morphological data (Kirsch 1977, Reig et al. 1987). However, if we consider the cladogram of Fig. 2, it is clear that the whole group of species with $2 \mathrm{n}=22$, might be explained by only one hypothetical common ancestor (HTU 8 of Figure 2). Although we cannot solve the problem of the plesiomorphic state of the Didelphidae family, it seems that the low diploid number species analysed $(2 n=14$ and $2 n=18$ ) are closely related, and that the origin of all the $2 n=22$ species can be explained with one hypothetical common ancestor. $L$. crassicaudata is the $2 n=22$ species most closely associated to the group of low diploid number.

However, despite of having a diploid set of 22 , the X chromosome of $L$. crassicaudata differs from the $\mathrm{X}$ of all other known Didelphis in being fully metacentric 
(Reig et al. 1977, 1987). Inasmuch, the morphological characteristics of L. crassicaudata have led these authors to place this species as the most specialized living didelphids. On the other hand, and in agreement with the fact that L. crassicaudata has distinct neurological characteristics (eg Pirlot et al. 1996) with respect to Didelphis, $L$. crassicaudata has been considered as a narrow-niche specialist.

$M$. dimidiata's karyotype $(2 \mathrm{n}=18)$ is intermediate between the $2 \mathrm{n}=14$ and $2 \mathrm{n}=22$ of the remaining species. Although allozyme data grouped $M$. dimidiata, $L$. crassicaudata and L. halli together, it is not possible to infer the trend of evolution within these taxa, and thus the direction of chromosomal evolution within the didelphids remains controversial. Reig et al. (1977) believe that the ancestral state for marsupials was the $2 \mathrm{n}=14$ karyotype giving place through Robertsonian fissions to the $2 \mathrm{n}=18$ and 22 karyotypes. This hypothesis is in contradiction with Sharman (1961) who proposed that chromosomal evolution among marsupials had progressed through a series of reductions from the diploid number of 22 as represented by $D$. virginiana giving place to the $2 \mathrm{n}=18$ and 14 karyotypes. However in a report where didelphimorph marsupials were grouped on the basis of anatomical, cytogenetic and serological studies, $L$. halli not only was related to Monodelphis Burnett (1830) but also Didelphis was closely related to L. crassicaudata (Reig et al. 1985).

The existence of species with a brief life span and small body size such as $L$. halli and M. dimidiata (Marmosini tribe) and species with a long life span and large body size (Didelphini tribe) allowed us to test the hypothesis which relates short generation-time with high genetic variability. It was not possible to validate this hypothesis since species from the Marmosini tribe showed lowest $H$ values with respect to the Didelphis sp. or L. crassicaudata (long life span taxa) analysed in our study. Therefore, genetic variability rates and generation time are uncorrelated in any way among opossums. However, it is important to highlight the small sample size of $L$. halli used in our study, which could have led to an underestimation of its $H$ value. $L$. halli is a monospecific genus, very difficult to capture, known through morphological descriptions of only 5 individuals all over the world. Among the Didelphidae, $M$. dimidiata provides an even more extreme test, since trapping data indicate that both males and females live only a single year. Litter sizes of Monodelphis are high but small bodied. Anyhow, studies about the rates of single-copy DNA evolution in Phalangeriform Marsupials (Springer and Kirsch 1989) have shown counterexamples to the common view that rates of changes in DNA sequences (and therefore genetic variability) are inversely correlated with generation time. On the whole, the need is demonstrated for taking additional parameters into account in characterising "generation time".

Representatives from the Didelphidae family were also used as a model to test the relationships between the brady-tachytelic conditions, the karyotype stability found in this group (Reig et al. 1977) and genetic variability. The genetic variability found in tachytelic species such as Akodontine rodents (Barrantes et al. 1993) or species of the genus Ctenomys (Ortells and Barrantes 1994), using exactly the same 
methodology, sets of proteins and performed in the same laboratory, was comparable to the variability found in our bradytelic samples composed by Didelphis sp. and $L$. crassicaudata. In agreement with Reig et al. (1977), bradytely and chromosomal uniformity in Didelphidae can be considered a causally linked phenomena explained by the high overall adaptive value of early acquired systems of gene regulation.

\section{Conclusions}

We conclude that a general explanation for genetic variability must involve more than just generation-time. Cellular repair mechanisms, cell generation-time, phylogeny, and perhaps genome structure should all be taken into account. The karyotypic conservatism among marsupials makes them an ideal group for study, since the most obvious candidate for such structural differences in genome organisation is held almost constant. Reig et al. (1977) argued that the anatomical conservatism of opossums may be a consequence of their severe karyotypic uniformity. But it is known that opossums have a mean rate of DNA evolution similar to that of other marsupials (Kirsch et al. 1991) and we have demonstrated in the present work that genetic variability values in Didelphidae were comparable to those found in taxa with high karyotype variability (Ortells and Barrantes 1994). Thus, both anatomical and karyological conservatism is accompanied by a normal or greater turnover in DNA sequence (Kirsch et al. 1991) and genetic variability (this study).

Although we cannot solve the problem of the plesiomorphic state of the Didelphidae family, it is clear that the low diploid number species analysed $(2 n=14$ and $2 n=18$ ) are closely related, and that the $2 n=22$ lineage has only one origin.

Acknowledgements: We are grateful to $\mathrm{M}$. Ortells for critically reading the manuscript. Financial support was made available by the Consejo Nacional de Investigaciones Científicas y Técnicas (CONICET), Argentina, through a Grant given to O. A. Reig. We thank to Dr O. P. Pearson who kindly provided the sample of Lestodelphys halli. We are grateful to Prof J. Kirsch for interesting discussions regarding our data.

\section{References}

Barrantes G. E., Ortells M. O. and Reig O. A. 1993. New studies on allozyme genetic distance and variability in akodontine rodents (Cricetidae) and their systematic implications. Biological Journal of the Linnean Society 48: 283-298.

Baverstock P. R., Cole S. R., Richardson B. J. and Watts C. H. S. 1979. Electrophoresis and cladistics. Systematic Zoology 28: 214-219.

Baverstock P. R., Watts C. H. S., Adams M. and Gelder M. 1980. Chromosomal and electrophoretic studies of Australian Melomys (Rodentia: Muridae). Australian Journal of Zoology 28: 553-574.

Baverstock P. R., Watts C. H. S. and Cole S. R. 1977. Electrophoretic comparisons between allopatric populations of five Australian pseudomyine rodents (Muridae). Australian Journal of Biological Sciences 30: 471-485.

Clemens W. A. 1968. Origin and early evolution of marsupials. Evolution 22: 1-18.

Clemens W. A. 1979. Marsupialia. [In: Mesozoic mammals. J. A. Lillegraven, Z. Kielan-Jaworowska and W. A Clemens, eds]. University of California Press, Berkeley: 192-220.

Gardner A. L. 1973. The systematics of the genus Didelphis (Marsupialia: Didelphidae) in North and Middle America. Special Publications of the Museum, Texas Technical University 4: 1-81. 
Kirsch J. A. W. 1977. The comparative serology of Marsupialia and a classification of marsupials. Australian Journal of Zoology 52: 1-152.

Kirsch J. A. W., Dickerman A. W., Reig O. A. and Springer M. S. 1991. DNA hybridization evidence for the Australasian affinity of the American marsupial Dromiciops australis. Proceedings of the Natlional Academy of Sciences of the USA 88: 10465-10469.

Lillengraven J. A. 1969. Latest Cretaceous mammals of upper part of Edmonton Formation of Alberta, Canada, and review of marsupial-placental dichotomy in mammalian evolution. University of Kansas Paleontological Contributions, Vertebrata 50: 1-122.

Mickevich M. F. and Johnson M. S. 1976. Congruence between morphological and allozyme data in evolutionary inference and character evolution. Systematic Zoology 25: 260-270.

Nei M. 1972. Genetic distance between populations. The American Naturalist 106: 283-292.

Nei M. 1978. Estimation of average heterozygosity and genetic distance from a small number of individuals. Genetics 89: 583-590.

Ortells M. O. and Barrantes G. E. 1994. A study of genetic distances and variability in several species of the genus Ctenomys (Rodentia: Octodontidae) with special reference to a probable causal role of chromosomes in speciation. Biological Journal of the Linnean Society 53: 189-208.

Pirlot P., Affanni J. M. and Benítez I. 1996. Brain size in Didelphids: new data from L. crassicaudata. [In: Animals in their environment. T. Cabana, ed]. Bibliothèque Nationale du Québec, Québec: 143-151.

Reig O. A. and Bianchi N. O. 1969. The occurrence of an intermediate didelphid karyotype in the short-tailed opossum (genus Monodelphis). Experientia 25: 1210-1211.

Reig O. A., Fernández R. D. and Spotorno A. O. 1972. Further occurrence of a karyotype of $2 \mathrm{n}=14$ chromosomes in two species of Chilean Didelphoid Marsupials. Zeitschrift für Säugetierkunde 37: 37-42.

Reig O. A., Gardner A. L., Bianchi N. O. and Patton J. L. 1977. The chromosomes of the Didelphidae (Marsupialia) and their evolutionary significance. Biological Journal of the Linnean Society 9: 191-216.

Reig O. A., Kirsch J. A. W. and Marshall L. G. 1985. New conclusions on the relationships of the opossum-like marsupials, with an annotated classification of the didelphimorphia. Ameghiniana 21: 335-343.

Reig O. A., Kirsch J. A. W. and Marshall L. G. 1987. Systematic relationships of the living and neocenozoic American "oppossum-like" marsupials (suborder didelphimorphia), with comments on the classification of these and of the cretaceous and paleocene new world and European metatherians. [In: Possums and opossums: Studies in evolution. M. Archer, ed]. Australia, Chipping Norton: (1) 1-89.

Richardson B. J., Johnston P. G., Clarke P. and Sharman G. B. 1973. An evaluation of electrophoresis as a taxonomic method using comparative data from the Macropodidae (Marsupialia). Biochemical Systematic and Ecology 1: 203-209.

Rogers J. S. 1972. Measure of genetic similarity and genetic distance. University of Texas Publications 7213: 145-153.

Sharman G. B. 1961. The mitotic chromosomes of marsupials and their bearing on taxonomy and phylogeny. Australian Journal of Zoology 9: 38-60.

Sneath P. H. A. and Sokal R. R. 1973. Numerical taxonomy. The principles and practice of numerical classification. W. H. Freeman and Company, San Francisco: 1-573.

Springer M. S. and Kirsch J. A. W. 1989. Rates of single-copy DNA Evolution in Phalangeriform Marsupials. Molecular Biology and Evolution 6: 331-341.

Swofford D. L. 1985. PAUP. Phylogenetic analysis using parsimony, version 2.4. Illionois Natural History Survey, Champaign, Illinois.

Swofford D. L. and Selander R. B. 1981. BIOSYS-1: A Fortran program for the comprehensive analysis of electrophoretic data in population genetics and systematics. Journal of Heredity 72: 281-283.

Wainberg R. L. and Fronza T. G. 1969. Análisis métrico de los cromosomas somáticos de Lutreolina crassicaudata paranalis Thomas (Marsupialia, Didelphidae). Physis 29: 261-267.

Received 9 June 1997, revised 14 January 1999, accepted 17 March 1999. 